\title{
JUIZADOS ESPPECIAIS CRIMINAIS: DA JUSTIÇA CONSENSUAL À CONSTRUCÃO DA SOLUCÃO DO CONFLITO: UM ESTUDO EM HOMENAGEM AO PROFESSOR DOUTOR LUIS ALBERTO WARAT, NOS CINCO ANOS DE SEU FALECIMENTO E NOS 20 ANOS DE VIGÊNCIA DA LEI No 9.099/1995
}

SUMÁRIO: Introdução; 2 Juizados Especiais Criminais: Entre "O Fim do Conflito" e "O Fim do Processo"; 3 Uma Crítica aos Mecanismos de Justiça Penal Consensual; 4 Superando as Limitações da Judicialização dos Conflitos: Olhando adiante; 5 Considerações Finais; Referências.

RESUMO: Uma visão crítica sobre os Juizados Especiais Criminais, por ocasião dos vinte anos de vigência da Lei $\mathrm{n}^{\circ} 9.099 / 1995$, pretendendo oferecer uma análise do processo preliminar e da eficácia dos mecanismos de justiça consensual que introduziu no ordenamento jurídico brasileiro, buscando projetar para o futuro uma perspectiva de adoção de instrumentos de justiça restaurativa, tomando como base os ensinamentos de Luis Alberto Warat sobre mediação.

PALAVRAS-CHAVE: Composição dos Danos Civis; Juizados Especiais Criminais; Justiça Restaurativa; Mediação; Transação Penal.

\section{SPECIAL CRIMINAL COURTS: FROM CONSENSUAL JUSTICE TO THE CONSTRUCTION OF A SOLUTION: A STUDY TO HONOR THE MEMORY OF PROFESSOR DR LUIS ALBERTO WARAT ON THE FIFTH YEAR OF HIS DEATH AND ON THE 20TH YEAR OF THE LAW 9099/1995}

\begin{abstract}
A critical analysis on Special Criminal Courts on the 20th year of Law 9099/1995 is undertaken. The preliminary process and the efficiency of mechanisms in consensual justice are provided. The introduction of Brazilian juridical ordering is investigated with a future perspective on the adoption of restoration justice based on the teachings of Luis Alberto Warat on mediation.
\end{abstract}

KEY WORDS: Special Criminal Courts; Composition of Civil Harm; Penal Transaction; Mediation; Restoration Justice.

Mestre em Direito pela Universidade Federal de Pernambuco (UFPE); Docente da Escola Superior do Ministério Público do Estado do Maranhão e da Unidade de Ensino Superior Dom Bosco (UNDB), Brasil. E-mail: cfrazao@mpma.mp.br 


\section{JUZGADOS ESPECIALES CRIMINALES: DE LA JUSTICIA CONSENSUAL A LA CONSTRUCCIÓN DE LA SOLUCIÓN DEL CONFLICTO. UN ESTUDIO EN HOMENAJE AL PROFESOR DOCTOR LUIS ALBERTO WARAT, EN LOS CINCO AÑOS DE SU FALLECIMIENTO Y EN LOS 20 AÑOS DE LA VIGENCIA DE LA LEY No 9.099/1995}

RESUMEN: Una visión crítica de los Juzgados Especiales Criminales, por ocasión de los veinte años de vigencia de la Ley $\mathrm{n}^{0} 9.099 / 1995$, objetivando ofrecer un análisis del proceso preliminar y de la eficacia de los mecanismos de la justicia consensual que introdujo en el ordenamiento jurídico brasileño, buscando proyectar para el futuro una perspectiva de adopción de instrumentos de justicia restaurativa, tomando como base la enseñanza de Luis Alberto Warat sobre mediación.

PALABRAS-CLAVE: Juzgados Especiales Criminales; Composición de los Daños Civiles; Transacción Penal, Mediación, Justicia Restaurativa.

\section{INTRODUÇÃO}

Muito embora se tenha experimentado, especialmente desde a década de 1990, uma hipertrofia do âmbito do direito penal (sobretudo desde a edição da Lei de Crimes Hediondos), esse movimento se deu em relação de concomitância com outro movimento no sentido da redução desse campo, sendo apresentada como exemplo desse fenômeno a Lei $\mathrm{n}^{0}$ 9.099, de 26 de setembro de 1995, que instituiu os Juizados Especiais Cíveis e Criminais, sucessores da experiência dos Juizados de Pequenas Causas (Lei $\mathrm{n}^{\circ}$ 7.244/1984).

O presente artigo, no marco dos vinte anos de vigência da Lei dos Juizados Especiais Cíveis e Criminais, pretende analisar se, no âmbito penal, os mecanismos despenalizadores e consensuais trazidos ao ordenamento jurídico brasileiro são capazes de promover a resolução dos conflitos a eles submetidos ou se, mais propriamente, não teriam senão a finalidade de representar um meio de "desafogar" o Poder Judiciário.

É preciso que se diga, nessa altura, que a crítica a um instituto - ou, de resto, ao que quer que seja - não supõe, necessariamente, sua superação ou a diminuição de sua importância, naquilo a que se propõe, mas, sim, o afastamento do discurso de certezas que frequentemente perpassa a produção teórica no campo do 
direito. Em outras palavras, criticar é colocar em crise o significado, pretensamente unívoco, representado pelo texto, ou, lembrando Roland Barthes, é "por em crise toda enunciação, aí incluída ela própria"1.

Para isso, inicia-se por discutir a visão corrente sobre os objetivos da Lei $\mathrm{n}^{\mathrm{o}} 9.099 / 1995$, seguindo-se uma breve discussão sobre o contexto em que foi concebida, sobre a natureza dos institutos inovadores por ela introduzidos e as críticas possíveis.

A partir daí, pretende-se chegar a sugestões para o futuro, tomando-se por guia a ideia de mediação desenvolvida pelo Professor Doutor Luis Alberto Warat, a quem se faz, aqui, uma homenagem, neste que será o quinto ano de seu falecimento.

Jurista e pensador argentino que, ao longo de sua vida, transitou por múltiplas áreas do conhecimento, desde a sociologia e o direito até a semiologia, a arte e a psicanálise, Luis Alberto Warat, doutor em Direito pela Universidade de Buenos Aires, Argentina, e pós-doutor pela Universidade de Brasília, lecionou por mais de 40 anos em diversas universidades de seu país natal e do Brasil, onde se radicou e onde foi professor titular da Universidade Federal de Santa Maria (RS), coordenador e professor de Direito da Unisul-Tubarão (SC), professor titular de Pós-Graduação em Direito da Universidade Federal de Santa Catarina, do Mestrado e do Doutorado em Direito na Unisinos, dentre outras instituições. Foi ele, também, fundador da Associação Latino-americana de Metodologia do Ensino do Direito (Almed), na década de 1970, e Presidente da Associação Latino-americana de Mediação, Metodologia e Ensino no Direito². Não obstante a isso, segue sendo muito pouco estudado no país de adoção. Segundo pontuado por Zanatta,

Warat reivindicava um saber crítico do direito através de um novo ponto de vista epistemológico, que tinha por objeto de análise os discursos competentes da ciência - o "senso comum teórico dos juristas" - e epistemologia jurídicas. Neste sentido, a meta inicial de um saber crítico seria a de caracterizar e explicitar o senso comum teórico dos juristas ${ }^{3}$.

${ }^{1}$ BARTHES, Roland. Théorie du texte. Atelier des Sciences du Langage de l'Université Paul-Valéry - Montpellier 3. Eléments de linguistique et de communication. Disponível em: < http://asl.univ-montp3.fr/e41slym/Barthes_THEORIE_DU_TEXTE.pdf $>$. Acesso em: 03 maio 2015.

${ }^{2}$ MORRE professor argentino Luis Alberto Warat. Consultor Jurídico, 17 de dezembro de 2010. Disponível em: $<$ http://www.conjur.com.br/2010-dez-17/morre-teorico-professor-argentino-luis-alberto-warat $>$. Acesso em: 03 maio 2015.

3 ZANATTA, Rafael. Luis Alberto Warat: contra o senso comum teórico dos juristas. E-MANCIPAÇÃO, 16 de dezembro de 2010. Disponível em: < http://rafazanatta.blogspot.com.br/2010/12/luis-alberto-warat-contra-osenso-comum.html > . Acesso em: 03 maio 2015. 
É ainda esse professor paulista quem revela:

Na opinião do português Boaventura de Sousa Santos (este sim, muito lido na sociologia jurídica), quem não conhece Warat sabe muito pouco sobre filosofia jurídica latino-americana, que vai muito além do mistificado Miguel Reale. Independentemente da qualidade ou sofisticação teórica produzida pelo pensador argentino, falecido em dezembro de 2010, o fato é que Warat, portenho que optou viver no Brasil e dedicar-se à estruturação da pós-graduação em Direito no país, produziu obras importantes sobre filosofia do direito, a relação entre direito e arte e formas mais humanas de solução de conflitos, como a mediação, "capaz de produzir devires de sensibilidade", como ele mesmo dizia ${ }^{4}$.

É com os olhos voltados para esse legado que o presente ensaio tem a ambição de oferecer a oportunidade de se pensar, desde um outro ângulo, os Juizados Especiais Criminais e, a partir daí, vislumbrar novas possibilidades para alcançar aquilo que é anunciado como seu desiderato, isto é, a pacificação dos conflitos criminalizados que alcança.

\section{JUIZADOS ESPECIAIS CRIMINAIS: ENTRE “O FIM DO CONFLITO” E “O FIM DO PROCESSO"}

$\mathrm{Na}$ lição de Grinover as alterações promovidas pela Lei no 9.099/1995 no processo penal brasileiro tiveram "o intuito de alcançar um 'processo de resultados', ou seja, um processo que disponha de instrumentos adequados à tutela de todos os direitos, com o objetivo de assegurar praticamente a utilidade das decisões. Trata-se do tema da efetividade do processo, em que se põe destaque na instrumentalidade do sistema processual em relação ao direito material e aos valores sociais e políticos da Nação"s.

A percepção, nesse sentido, de que o tratamento de certas condutas incriminadas, de pequena repercussão jurídico-penal, sem se levar em conta essa sua característica, favorecia a estigmatização do indivíduo, a superpopulação carcerária

\footnotetext{
$\overline{4}$ ZANATTA, Rafael. O que é o movimento waratiano? E-MANCIPAÇÃO, 5 de setembro de 2012. Disponível em: <http://rafazanatta.blogspot.com.br/2012/09/o-que-e-o-movimento-waratiano.html > . Acesso em: 3 maio 2015.

5 GRINOVER, Ada Pellegrini; GOMES FILHO, Antônio Magalhães; FERNANDES, Antônio Scarance; GOMES, Luiz Flávio. Juizados especiais criminais. 2. ed. São Paulo: RT, 1997, p. 23.
} 
e a lentidão da prestação jurisdicional, criou as condições para a concepção de um sistema que privilegiasse o método consensual, a disponibilidade da ação penal pública (ainda que resultante da mitigação da obrigatoriedade), a oralidade, a informalidade e a celeridade, sendo esses os princípios ou as diretrizes que orientam o rito introduzido no ordenamento jurídico brasileiro pela Lei dos Juizados Especiais.

Mencionados mecanismos conciliatórios seriam representados, sobretudo, pela composição dos danos civis e pela transação penal, marcos do processo preliminar que, antecedendo o ajuizamento da ação penal, dão oportunidade para os envolvidos tomarem para si a resolução da situação conflitiva em que se viram envolvidos, quer seja compondo entre elas mesmas, no primeiro, quer seja compondo o autuado com o Ministério Público, no sentido da aplicação antecipada de uma pena restritiva de direitos.

Ainda conforme ensina Grinover as vantagens desse novo paradigma (doutrinário e legislativo) seriam várias. Em primeiro lugar, ter-se-ia a "participação popular na administração da Justiça, em respeito ao princípio democrático do envolvimento do corpo social na solução das lides", o que se compreenderia no momento da composição dos danos civis e da transação penal, rompendo com "o sistema fechado e piramidal da administração da Justiça exclusivamente feita pelos órgãos estatais". Em segundo lugar, a busca da solução conciliativa - e, portanto, não baseada no discurso de autoridade - do conflito criminalizado, permitiria uma maior aproximação da pacificação social, sendo, nesse contexto, também renovada a função do juiz, "que se tornaria um elemento de transformação, deixando de ser apenas um solucionador da controvérsia, em seu papel de ditar o direito, para assumir as vestes de um verdadeiro mediador de conflitos", possibilitando ao Poder Judiciário uma melhor distribuição de esforços, no sentido de "dedicar-se prioritariamente às infrações penais mais graves, que realmente estão a exigir toda sua atenção"6.

Finalmente, a priorização de uma justiça conciliatória valorizaria a figura da vítima, até então silenciada no processo penal, passando ela a assumir um papel ativo na satisfação de seus interesses cíveis e penais, favorecendo, também isso, a pacificação social. E concluem os mesmos autores:

Tudo isso, em última análise, inseria-se nas poderosas tendências rumo à deformalização do processo - tornando-o mais simples, mais

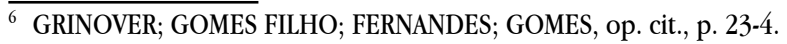


rápido, mais eficiente, mais democrático, mais próximo da sociedade - e à deformalização das controvérsias, tratando-as, sempre que possível, pelos meios alternativos que permitem evitar ou encurtar o processo, como a conciliação ${ }^{7}$.

Ada Pellegrini Grinover, Antônio Magalhães Gomes Filho e Antônio Scarance Fernandes - autores, ao lado de Luiz Flávio Gomes, dos comentários acima mencionados - integraram o grupo de trabalho que elaborou o anteprojeto, apresentado ao então Deputado Federal Michel Temer e que veio a transformar-se na Lei $n^{0}$ 9.099/1995, e essas suas observações revelam bem qual a vontade da lei, conforme acima reproduzido, isto é, promover a eficiência da prestação jurisdicional, no que diz respeito à abordagem jurídico-penal dos crimes de menor gravidade, alcançado esse objetivo pela via da simplicidade, informalidade, celeridade e participação democrática dos envolvidos no conflito, com favorecimento da pacificação social.

De fato, pode-se afirmar que a Lei dos Juizados Especiais Cíveis e Criminais inscreve-se em dois contextos que se completam.

Em primeiro lugar, apresenta-se como expressão do esforço de, através de mecanismos de despenalização e consensualidade, reduzir o efeito estigmatizante exercido sobre aqueles que são alcançados pelo sistema penal. Isso porque o que se observa, através da aplicação do sistema convencional-punitivo de justiça penal, ao lado do roubo do conflito ${ }^{8}$, é um crescente processo de estigmatização do indivíduo criminalizado9 ${ }^{9}$ através de toda uma teia de fenômenos que lhe dificulta ou mesmo

\footnotetext{
7 Ibidem, 1997, p. 24

${ }^{8}$ Entendido como "o esvaziamento do estatuto criminal da vítima, num sistema penal que veio a estruturar-se em termos diádicos delinquente-estado, pela via da hipostasiação dos interesses do estado e sua progressiva sub-rogação na posição originária da vítima" (ANDRADE, Manuel da Costa, op. cit., 1980, p. 331).

9 Sobre esse processo de estigmatização do indivíduo alcançado pelo sistema penal, ver: BECKER, op. it., 1973. Sobre o assunto, também: RIBEIRO, Cláudio Luiz Frazão Ribeiro. O mito da função ressocializadora da pena: a intervenção do sistema penal como fator de estigmatização do indivíduo criminalizado. São Luís: AMPEM, 2006.
} 
impede a ressocializaçãa ${ }^{10}$.

Em segundo lugar, é possível dizer que os Juizados Especiais também se revelam como resultado do que chamaram Cappelletti e Garth de terceira onda do acesso à justiça, que implicaria "uma ampla variedade de reformas, incluindo alterações nas formas de procedimento, mudanças na estrutura dos tribunais ou a criação de novos tribunais"11, assim como inovações no direito material e participação de profissionais especializados, tudo destinado a facilitar a solução dos litígios, sobretudo através da mediação e de outros métodos "apropriados para preservar os relacionamentos"12.

Não obstante aquela vontade da lei, revelada por seus idealizadores, não se pode ignorar que o direito como um todo, e não apenas o direito penal, vive um visível paradoxo representado pela falta de correspondência entre o momento de sua criação - no âmbito legislativo - e o momento de sua execução. E isso não significa que a ineficácia prática daquilo programado normativamente se deve, sempre, a uma incapacidade dos órgãos executores de implementar as previsões legais - seja devido à corrupção, à falta de vontade política ou às deficiências estruturais - ou a uma insensibilidade da parte dos órgãos criadores em evitar essa incongruência através de um melhor conhecimento da realidade e das dificuldades em concretizar aquilo previsto nas regras que produzem.

Funções e metas do direito que, tradicionalmente, são termos apresentados como sinônimos - significando suas consequências desejadas, isto é, normativas,

\footnotetext{
${ }^{{ }^{10}}$ Dentre esses fenômenos, encontram-se os estereótipos (DIAS, Figueiredo; ANDRADE, Manuel da Costa. Criminologia: o homem delinquente e a sociedade criminógena. Coimbra: Coimbra, 1992, p. 348), a interpretação retrospectiva e a reconstrução biográfica (GOFFMAN, Erving. Estigma: notas sobre a manipulação da identidade deteriorada. 4. ed. Rio de Janeiro: Guanabara, 1988, p. 73), as status-degration ceremonies e as instituições totais e o role-engulfment (DIAS ANDRADE, op. cit, p. 353). Como disse em outra ocasião, "torna-se mais claro o processo de estigmatização a que é sujeitado o indivíduo rotulado como criminoso, e que desencadeia uma série de associações e mecanismos que o levam a conformar-se com e a moldar-se a essa imagem, potencializando seu isolamento social e estreitando a sua margem de oportunidades legítimas e induzindo a procura por oportunidades ilegítimas. O tratamento que lhe é dispensado pelo sistema penal, distanciando-se cada vez mais de sua função ressocializadora declarada, não cumpre senão o papel de multiplicador da própria delinqüência que promete combater, uma vez que o indivíduo desviado passa a sofrer um verdadeiro role -engulfment -convertendo-se em arauto de sua própria condenação, significando que sua auto-imagem e sua interação social tendem a adequar-se a esse papel, delineado pelas instâncias de controle formal" (RIBEIRO, Cláudio Luiz Frazão. O mito da função ressocializadora da pena: a intervenção do sistema penal como fator de estigmatização do indivíduo criminalizado. São Luís: AMPEM, 2006, p. 134-5).

${ }^{11}$ CAPPELLETTI; GARTH, op. cit., 1988, p. 71.

${ }^{12}$ Os movimentos de garantia do acesso à Justiça, a partir, sobretudo, dos anos 1960, importaram em três "ondas" ou "soluções" para sua obtenção. A primeira consistiu na concessão de assistência judiciária aos pobres. A segunda, a possibilidade de defesa dos direitos coletivos e difusos. A terceira "onda", por sua vez, implicou a formação de um novo "conjunto geral de instituições e mecanismos, pessoas e procedimentos utilizados para processar e mesmo prevenir disputas nas sociedades modernas" (CAPPELLETTI; GARTH, op. cit., p. 72), isto é, para o efetivo acesso à Justiça, como instância de resolução pacífica de conflitos, não bastaria o acesso à assistência judiciária gratuita, seriam necessárias mudanças e inovações nas estruturas judiciárias e jurídicas já existentes, criação de novos tribunais etc (CAPPELLETTI; GARTH, op. cit., p. 70-71).
} 
hipótese exclusiva de que se ocupava o pensamento penal e criminológico passam, a partir das discussões em torno das consequências sociológicas do direito penal e da pena, notadamente de seu caráter simbólico, a poder ser definidas de maneira diversa: metas do direito corresponderiam às consequências oficialmente anunciadas e buscadas; funções como a soma das consequências objetivas de dada coisa, devendo ser entendida, no âmbito do direito, como seus efeitos não desejados ou - no sentido que se pretende empregar neste artigo - não anunciados como os verdadeiros ou prioritários ${ }^{13}$.

Assim, a meta anunciada pela Lei $\mathrm{n}^{0} 9.099 / 1995$ - e presente no discurso corrente a respeito dos Juizados Especiais Cíveis e Criminais, a ponto de constituir mesmo aquilo que Warat chama de o senso comum teórico dos juristas ${ }^{14}$ - é a promoção da pacificação social, através da resolução consensual do conflito, devolvendo, às partes envolvidas, o poder decisório sobre a situação problemática e a possibilidade de autocomposição.

Já a função que se revela ${ }^{15}$ a partir da análise do contexto do surgimento da Lei dos Juizados Especiais aponta para um objetivo mais comprometido com o mindset gerencialista, diante da necessidade de desoneração do Poder Judiciário, comumente referido como sobrecarregado de processos.

Com efeito, Cappelletti e Garth, na hoje clássica obra "Acesso à Justiça", já revelavam essa preocupação ao chamarem a atenção para a pressão existente sobre o Judiciário, "no sentido de reduzir a sua carga e encontrar procedimentos ainda

\footnotetext{
${ }^{13}$ LAVORENTI, Wilson; SILVA, José Geraldo da. Crime organizado na atualidade. Campinas: Bookseller, 2000, p. 140. No mesmo sentido: ANDRADE, Vera Regina Pereira de. A ilusão da segurança jurídica: do controle da violência à violência do controle penal. Porto Alegre: Livraria do Advogado, 1997, p. 293. Para Merton, essa distinção se dá através dos conceitos de função manifesta e função latente. Esclarece o autor haver adaptado os termos manifesto e latente a partir de seu uso, em outro contexto, por Freud, muito embora reconheça que, antes deste, já Francis Bacon falasse em processos latentes e configurações latentes em conexão com processos que se encontram por detrás da observação superficial. MERTON, Robert K. Social theory and social structure. Enl. ed., New York: The Free Press, 1968, p. 115.

${ }^{14}$ Explica Warat que "nas atividades cotidianas - teóricas, práticas, e acadêmicas - os juristas encontram-se fortemente influenciados por uma constelação de representações, imagens, pré-conceitos, crenças, ficções, hábitos de censura enunciativa, metáforas, estereótipos e normas éticas que governam e disciplinam anonimamente seus atos de decisão e enunciação. Pode-se dizer que estamos diante de um protocolo de enunciação sem interstícios. Um máximo de convenções linguísticas que encontramos já prontas em nós quando precisamos falar espontaneamente para reificar o mundo, compensar a ciência jurídica de sua carência. Visões, fetiches, lembranças, ideias dispersas, neutralizações que beiram as fronteiras das palavras antes que elas se tornem audíveis e visíveis, mas que regulam o discurso, mostram alguns dos componentes chaves para aproximar-nos da ideia do 'senso comum teórico dos juristas"'. WARAT, Luiz Alberto. Introdução geral do direito I: interpretação da lei: temas para uma reformulação. Porto Alegre: Fabris, 1994, v. 1, p. 14. Assim, pode-se entender esse senso comum teórico dos juristas como uma "para-linguagem, alguma coisa que está mais além dos significados, para estabelecer em forma velada à realidade jurídica dominante". Idem, p. 15.

${ }^{15}$ Aqui, cabe uma advertência: as ideias de metas e funções do direito ou dos institutos do direito não se encontram, necessariamente, em relação de oposição ou de exclusão nem significam uma relação maniqueísta, em que as metas representariam o bem e as funções, sua degeneração. Metas e funcões não são senão leituras possíveis do discurso jurídico sobre si mesmo.
} 
mais baratos", advertindo não se dever permitir que essa pressão "venha a subverter os fundamentos de um processo justo"16.

$\mathrm{Na}$ experiência brasileira, o antecedente legislativo frequentemente invocado como origem nacional dos Juizados Especiais, a Lei dos Juizados de Pequenas Causas (que, entretanto, não se aplicava à competência criminal), nasceu no contexto da desburocratização patrocinada pelo Poder Executivo, sendo marcado por uma identidade fortemente neoliberal. Isso porque o Programa Nacional de Desburocratização, instituído pelo Governo Federal em 1979, no início da década seguinte deixou de incluir somente o Poder Executivo para também alcançar o Judiciário, a quem cumpriria oferecer a prestação jurisdicional a partir de medidas desburocratizadoras que incluiriam o reaparelhamento humano e material da Justiça, a criação de juizados de pequenas causas (cíveis) - que resultaram na Lei $\mathrm{n}^{\mathrm{o}} 7.244 / 1984$ - e a descentralização da competência legislativa sobre matéria processual e de organização judiciária ${ }^{17}$. Como adverte Pereira:

No entanto, o judiciário é encarado como um prestador de serviços, e seu dever é prestá-los de modo 'rápido, barato e eficiente'. Ou seja, o escopo de ampliar o acesso à justiça parecia estar mais orientado a uma justiça de fluxo e pouco dispendiosa do que a uma justiça de qualidade: como se estas três características fossem suficientes para a promoção da cidadania e da efetivação de direitos por meio do acesso à justiçç ${ }^{18}$.

A mesma autora informa que a instituição dos Juizados de Pequenas Causas não foi fruto de uma movimentação de juristas, mas, sim, da iniciativa do Ministério da Desburocratização, como resultado das discussões no Programa Nacional de Desburocratização e de acréscimos trazidos pelos processualistas integrantes de comissão instituída, em 1981, presidida por João Geraldo Piquet Carneiro, da qual também participavam Kazuo Watanabe, Cândido Rangel Dinamarco, Caetano Lagrasta Neto, Ada Pellegrini Grinover e Paulo Salvador Frontini ${ }^{19}$.

As inovações previstas na prestação jurisdicional, nessa altura, consistiam, portanto, menos a garantia do efetivo acesso à Justiça do que a uma justiça de priorização da eficiência, no sentido econômico do termo.

\footnotetext{
${ }^{16}$ CAPPELLETTI; GARTH, op. cit., p. 164.

${ }^{17}$ CARNEIRO, João Geraldo Piquet. A justiça do pobre. Revista da Amagis, Belo Horizonte, v. 1, n. 1, p. 146-151, 1983.

${ }^{18}$ PEREIRA, Júlia Lafayette. Implicações do discurso eficientista neoliberal no movimento de ampliação do acesso à justiça: a experiência dos juizados especiais federais. 2013. 171f. Dissertação (Mestrado em Direito) - Programa de Pós-Graduação em Direito, Universidade do Vale dos Sinos, São Leopoldo.

${ }^{19}$ Ibidem, 2013, p. 26.
} 
Não se quer fazer crer que os Juizados, por esses motivos, são incapazes de promover o acesso qualificado à justiça. Contudo, deve-se dizer que os Juizados Especiais Estaduais e, mais tarde, os Juizados Especiais Federais, estão de certa forma vinculados a este contexto que lhes deu origem, pois são fruto da experiência paradigmática proposta nos Juizados de pequenas causas. A própria observação das Leis 7.244/84 e da Lei 9.099/95, a qual aderem os Juizados Especiais Federais no que com a Lei 10.259/01 não conflitar, não deixam dúvida disso diante das suas semelhanças ${ }^{20}$.

Não é possível, portanto, afirmar que se encontre afastada, no presente contexto, com a vigência das Leis $n^{0} 9.099 / 1995$ e $n^{0}$ 10.259/2001, a identidade neoliberal das inovações por elas inauguradas, reduzindo custos e alcançando metas estatísticas, opondo, com isso, a promessa de eficácia e a necessidade de eficiência.

\section{UMA CRÍTICA AOS MECANISMOS DE JUSTIÇA PENAL CONSENSUAL}

Como dito acima, a Lei $\mathrm{n}^{0} 7.244 / 1984$, que marcou um primeiro passo na instituição de uma justiça mais informal e, portanto, que se pretende mais acessível, não se originou da mobilização de juristas, mas do esforço de desburocratização estatal. E isso não causa surpresa.

Na América Latina, até a década de 1980, o Poder Judiciário não constituía uma instituição de destaque, tendo sua atuação inibida para que não interferisse nas práticas repressivas autoritárias. O Estado era baseado no fortalecimento do Poder Executivo e os juízes estavam reduzidos a meros aplicadores da lei, limitados pelo princípio inafastável da inércia, sendo o Poder Judiciário nada mais que parte do aparato da burocracia oficial, inteiramente incapaz de fazer frente à expansão dos mecanismos reguladores estatais ${ }^{21}$.

A superação do período autoritário, se de um lado recebeu a herança do prejuízo à sociabilidade e à capacidade associativa da população, dificultando a passagem do "indivíduo ao cidadão", testemunhou o desenvolvimento e a expansão do direito na direção "da construção da cidadania e da animação da vida

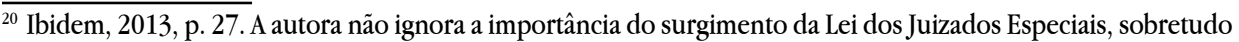
considerando a coincidência com a redemocratização do país havia pouco menos de uma década: "Nesse contexto, os Juizados surgem - ao menos aparentemente - como uma alternativa de justiça popular, democrática e participativa, almejando uma metodologia não-adversarial de solução de conflitos, amparada na conciliação e na arbitragem, sem, no entanto, comprometer as vias tradicionais de prestação jurisdicional. Entre os novos sujeitos processuais que surgem com os Juizados, como o juiz leigo, o conciliador, o árbitro, busca-se a realização de um "maior intercâmbio social", aproximando as bases populares da Justiça, que outrora encontravam uma restrita possibilidade de acesso nos moldes de justiça tradicionais. PEREIRA, op. cit., p. 21.

${ }^{21}$ SANTOS, Boaventura de Sousa. Para uma revolução democrática da justiça. 3. ed. São Paulo: Cortez, 2011, p. 21.
} 
republicana"22.

É a partir dos anos 1980, naquele movimento da "terceira onda" de que fala Cappelletti, que, mesmo tardiamente, no Brasil, incluem-se os Juizados Especiais Cíveis e Criminais, materializando as reformas tendentes a informalizar o acesso à Justiça. Mais especificamente no que diz respeito aos Juizados Especiais Criminais, os mecanismos inaugurados pela Lei $\mathrm{n}^{0}$ 9.099/1995 representaram a mitigação do princípio da obrigatoriedade da ação penal pública, ao permitir que a composição dos danos civis e a transação penal sejam causa de extinção da pretensão punitiva do Estado.

No primeiro caso, da composição dos danos civis, prevista no artigo 72 da Lei $\mathrm{n}^{\circ}$ 9.099/1995, essa corresponde a um acordo entre os envolvidos, que, homologado pelo juiz, tem por consequência a declaração de extinção da punibilidade do agente. Quanto à transação penal, disciplinada no artigo 76 da mesma lei, essa constitui, desde que atendidas as condições legais, na proposta, pelo Ministério Público, de aplicação imediata de uma pena restritiva de direito ou multa, gerando, igualmente, a extinção da punibilidade do autuado.

Como se observa, o que a lei prevê é a instituição do espaço do consenso onde, antes, só havia lugar para a justiça punitiva.

Passados vinte anos de vigência da Lei $n^{0}$ 9.099/1995, não se manteve ela imune a críticas. Essas, entretanto, no âmbito dos Juizados Especiais Criminais e no que diz respeito aos institutos da composição dos danos civis e da transação penal, costumam concentrar-se, basicamente, na alegação de inconstitucionalidade dessas medidas, especialmente por agressão aos princípios do devido processo legal e da presunção de inocência - tendo em vista que haveria verdadeira condenação sem processo. Não é dessa crítica que se pretende tratar no presente artigo, mas, sim, da capacidade potencial de tais mecanismos efetivamente promoverem aquele espaço do consenso, livre - o quanto possível - dos elementos estigmatizadores próprios do paradigma punitivo.

Mencionada incapacidade - não se pode dizer que sem um importante grau de propriedade - foi exposta por Karan, para quem, no caso da transação penal não haveria, na verdade, uma negociação que suporia a autonomia e a igualdade entre as partes envolvidas, tendo em vista que o autor do fato não se encontraria em igualdade de condições com seu acusador ${ }^{23}$.

\footnotetext{
${ }^{22}$ VIANNA, Luiz Werneck; MELO, Manuel Palacios Cunha; CARVALHO, Maria Alice Rezende de. A judicialização da política e das relações sociais no Brasil. 2. ed. Rio de Janeiro: Revan, 1999, p. 153.

${ }^{23}$ KARAN, Maria Lúcia. Juizados especiais criminais: a concretização antecipada do poder de punir. São Paulo: RT, 2004, p. 39.
} 
Como esclarece Kyle, também a partir de Karan, não há ajuste entre as partes, mas, sim, verdadeira "chantagem":

[‥]. O Ministério Público propõe os termos do acordo, e a outra parte aceita ou se sujeita ao processo regularmente desenvolvido; dessa forma, ao indigitado autor da infração restam poucas alternativas. Segundo a autora [Maria Lúcia Karan], "trata-se, pois de uma negociação cujo escopo é fazer com que uma das partes tenha sempre assegurada sua satisfação, nada tendo a perder, enquanto a outrem além de negociar sob pressão, nada terá a ganhar"24.

Ainda quanto à transação penal, o fato de ser ela proposta quando, diante da precariedade dos Termos Circunstanciados de Ocorrência, ainda não se tem conhecimento da viabilidade da acusação, leva o imputado a decidir sobre a oferta de aplicação antecipada de uma pena, sem que disponha de condições objetivas para avaliar se lhe é mais vantajoso aceitá-la ou, pelo contrário, se é mais conveniente rejeitá-la, diante do prognóstico de maior ou menor probabilidade de procedência da ação penal. Pode-se dizer, com isso, que a resposta do autuado diante da proposta formulada pelo Ministério Público é uma decisão às cegas.

Na verdade, diante de uma investigação policial irremediavelmente deficiente ou diante de elementos probatórios que retirariam justa causa para a acusação, não se poderia esperar do Ministério Público outra solução senão o imediato pedido de arquivamento do Termo Circunstanciado de Ocorrência, antes mesmo da audiência preliminar, não sendo razoável, mesmo que em nome de suposta pacificação social, submeter o imputado aos eventuais ônus decorrentes da aceitação de proposta de composição dos danos civis ou de transação penal. Cabe, neste ponto, a advertência de Mendes:

O Estado está vinculado ao dever de respeito e proteção do indivíduo contra exposição a ofensas ou humilhações. A submissão do homem a processos judiciais indefinidos atenta contra o princípio da proteção judicial efetiva, além de ferir o princípio da dignidade humana. Assim, não se afigura admissível o uso do processo penal como substitutivo de uma pena que se revela tecnicamente inaplicável ou a preservação de ações penais ou de investigações criminais cuja inviabilidade já se divisa de plano ${ }^{25}$.

No que se refere à composição dos danos civis, antecedente à transação

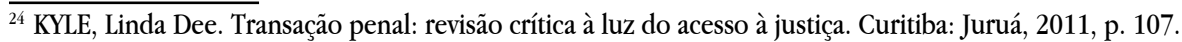

${ }^{25}$ MENDES, Gilmar Ferreira. Apresentação. In: HASSEMER, Winfried. Direito penal libertário. Belo Horizonte: Del Rey, 2007, p. xiii.
} 
penal, e é conduzida por conciliador, esse tem margem bastante limitada de atuação para não lhe permitir ir além do mero esforço de obter uma renúncia ao exercício do direito de queixa ou de representação por parte da vítima ou um acordo de natureza patrimonial, de modo a evitar o prosseguimento do litígio - inclusive na instância cível, se integralmente satisfeita, nessa ocasião, a pretensão indenizatória. Acrescentese a isso o fato de a audiência preliminar em que é promovida essa tentativa de composição contar com a previsão da presença do juiz, sob cuja orientação age o conciliador, e do promotor de justiça (Lei ${ }^{0}$ 9.099/1995, art. 72 e seguintes), o que continua a expor as partes em conflito à austeridade e à formalidade do ato judicial, a que de fato corresponde, o que, por óbvio, não favorece a tentativa de verdadeira reconstrução da proximidade entre os envolvidos na situação problemática, de modo inclusive a evitar futuros confrontos mais graves, tendo em vista que, em geral, os contendores - sobretudo no caso de crimes contra a honra ou de crimes de ameaça - mantinham algum nível de relacionamento abalado ou destruído pela situação problemática que os levou até ali.

Além disso, é preciso que se diga que duas outras circunstâncias se associam para dificultar alcançar-se a pacificação ou a solução do conflito pela via consensual, nos moldes atualmente definidos na fase preliminar do procedimento dos Juizados Especiais Criminais. Em primeiro lugar, ao conciliador não é exigida formação outra senão a jurídica, restando claro que, à parte de interesse e esforço pessoais em ir além, não buscará senão a eventual obtenção de acordo - frequentemente patrimonial - entre as partes, de modo a por fim ao processo.

Em segundo lugar, não é raro que a assistência jurídica ao imputado enfrente graves dificuldades, como no caso da cidade de São Luís, capital do Estado do Maranhão, onde, ao contrário da maioria das varas do juízo comum criminal, nem um dos três Juizados Especiais Criminais ali instalados conta com atuação de defensor público, obrigando contar-se com a colaboração voluntária de advogados que aceitam ser nomeados defensores dos autuados hipossuficientes ${ }^{26}$. É pertinente, nesta altura, a observação de Viana:

A Justiça Consensual constituiu, sim, importante inovação introduzida pela Constituição Federal, atendendo aos fins do Estado Democrático de Direito, menos burocrático e mais eficiente, modernizando o sistema vigente e abandonando as concepções conservadoras e burocráticas que denegriam a imagem do Judiciário. Mas, o que se vislumbrou na realidade, diante da execução deste projeto e atenta análise ao funcionamento dos Juizados Especiais, foi a utilização da

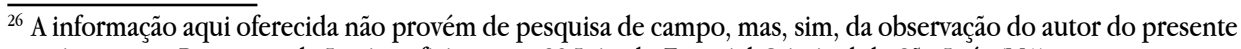
artigo, como Promotor de Justiça oficiante no $3^{\circ}$ Juizado Especial Criminal de São Luís (MA). 
lei que o instituíra como instrumento de redução do expediente forense, buscando-se a todo custo aplicar a justiça consensual, sem, contudo, atentar para o anseio constitucional de criar formas alternativas de aplicação do Direito Penal e Civil, sem o desgaste processual e com eficiência, o que, via de consequência, acabou por banalizar os novos institutos ${ }^{27}$.

Portanto, a partir dessa sucinta crítica, pode-se perceber que a composição dos danos civis e a transação penal tendem mais propriamente a ser manejadas como mecanismos de barreira da judicialização penal de conflitos sociais, cumprindo o objetivo de pacificação social apenas simbolicamente. Quando de fato tenha por efeito a superação da situação problemática existente entre os envolvidos, isso se deve menos à capacidade potencial daqueles mecanismos do que ao esforço pessoal dos interessados, do conciliador, dos advogados, do promotor de justiça e do juiz.

Em suma, de maneira mais ou menos consciente ou mais ou menos explícita, os objetivos da lei são considerados atingidos com o "fim do processo" e não com o "fim do conflito"28.

\section{SUPERANDO AS LIMITAÇÕES DA JUDICIALIZAÇÃO DOS CONFLITOS: OLHANDO ADIANTE}

Uma maneira de superar as limitações representadas pelo atual modelo de justiça consensual oferecido pelos mecanismos da composição dos danos civis e da transação penal, para a abordagem da pequena criminalidade - e que poderia, até mesmo, ser expandida para a chamada média criminalidade, atualmente representada pelos crimes com pena máxima abstratamente cominada não superior a dois anos de privação da liberdade (Lei no 9.099/1995, art. 89, caput) - seria a introdução de um novo modelo de mediação, que, sem necessariamente ser concebida como uma atividade jurisdicional, promovesse a efetiva resolução dos conflitos, favorecendo a proximidade entre os envolvidos e o (re)conhecimento do conflito latente, subjacente à situação problemática que vem à superfície.

\footnotetext{
${ }^{27}$ VIANA, Fábia de Kássia Mendes. Os juizados especiais como mecanismo de acesso à justiça. Via Jus. Disponível em: $<$ http://www.viajus.com.br/viajus.php?pagina $=$ artigos\&id $=553 \&$ idAreaSel $=16 \&$ seeArt $=$ yes $>$. Acesso em: 03 maio 2015.

${ }^{28} \mathrm{O}$ direito, diferentemente de outras instâncias de controle (sociais, religiosas, morais), seria apenas capaz de decidir conflitos e não de solucioná-los. Conforme observa Ferraz Júnior, "isto significa, simplesmente, que a decisão jurídica (a lei, a norma consuetudinária, a sentença do juiz etc.) impede a continuação de um conflito: ela não o termina através de uma solução, mas o soluciona pondo-lhe um fim. Pôr-lhe um fim não quer dizer eliminar a incompatibilidade primitiva, mas trazê-la para uma situação onde ela não pode mais ser retomada nem levada adiante (coisa julgada)", como que atribuindo à sentença o poder mágico de modificar a realidade através de sua simples prolação. FERRAZ JÚNIOR, Tércio Sampaio. A ciência do direito. 2. ed. São Paulo: Atlas, 1980, p. 91.
} 
De fato, pode-se entender a mediação de duas maneiras. A primeira seria correspondente a um modelo que se pode classificar como acordista, tendo como objetivo atingir uma solução, aceita por todos os envolvidos, para um conflito que é concebido como um problema a ser resolvido. Esse modelo, não é difícil vislumbrar, é aquele buscado quando do emprego das soluções previstas na fase preliminar do procedimento dos Juizados Especiais Criminais. Para aqueles que assim entendem a mediação, "os conflitos se solucionam redatando convênios"29.

Uma segunda visão seria a da mediação transformadora, isto é, da concepção do conflito como uma oportunidade de crescimento das partes, de melhora na qualidade de vida, enfim, como uma força positiva "na construção das relações sociais e na realização da autonomia individual [...], um incentivo para a interação, [...] numa possibilidade para criar, com o outro, a diferença" ${ }^{\sharp 0}$, não se revestindo, portanto, de uma natureza adversarial ${ }^{31}$.

\section{Sobretudo nesse último sentido, a mediação não pode ser pensada a partir}

${ }^{29}$ WARAT, Luiz Alberto. Ecologia, psicanálise e mediação. In: WARAT, Luiz Alberto (Org.). Em nome do acordo: a mediação no direito. Buenos Aires: ALMED, 1998, p. 15.

${ }^{30}$ WARAT, op. cit., p. 16.

${ }^{31}$ Esse modelo se aproxima do conceito de Justiça Restaurativa, desenvolvido especialmente por Howard Zehr, para quem, entretanto, "Justiça restaurativa não é mediação". No original: Restorative justice is not mediation. ZEHR, Howard; GOHAR, Ali. The little book of restorative justice. New York: Good Books, 2003, p. 7. E prossegue o mesmo autor: "Assim como programas de mediação, muitos programas de justiça restaurativa são concebidos em torno da possibilidade da facilitação de reuniões ou de encontros com o envolvimento de vítimas, ofensores e, às vezes, membros da comunidade. Apesar disso, um encontro nem sempre é a opção eleita ou a mais apropriada. Abordagens restaurativas são importantes mesmo quando o ofensor não se encontra detido ou quando uma das partes não deseja ou não pode delas participar. Portanto, abordagens restaurativas não se encontram limitadas àqueles encontros entre as partes. Mesmo quando um encontro ocorre, o termo 'mediação' é uma descrição problemática. Em um conflito mediado ou em uma disputa, as partes são compreendidas como encontrando-se em igualdade de condições morais, frequentemente com responsabilidades que devem ser compartilhadas. Embora esse sentido de 'culpa compartilhada' possa ser verdadeiro em alguns casos criminais, em muitos outros essa concepção não é possível. Uma vítima de estupro ou mesmo de roubo não quer ser identificada, nesses casos, como uma 'parte em disputa'. De fato, na verdade, elas podem estar lutando para superar a tendência de culpar a si mesmas. De qualquer modo, para participar da maioria dos encontros de justiça restaurativa, o malfeitor deve admitir algum nível de responsabilidade pela ofensa, e um importante componente desses programas é nomear e reconhecer o malfeito. A linguagem neutra da mediação pode se revelar ambígua e mesmo ofensiva em alguns casos. Apesar de o termo 'mediação' ter sido adotado em um primeiro momento nesse campo, tem sido, pelas razões acima, cada vez mais substituído por termos como 'conferência' ou 'diálogo'". No original: Like mediation programs, many restorative justice programs are designed around the possibility of a facilitated meeting or encounter between victims, offenders and perhaps community members. However, an encounter is not always chosen or appropriate. Moreover, restorative approaches are important even when an offender has not been apprehended or when a party is unwilling or unable to meet. So restorative approaches are not limited to an encounter. Even when an encounter occurs, the term 'mediation' is a problematic description. In a mediated conflict or dispute, parties are assumed to be on a level moral playing field, often with responsibilities that may need to be shared on all sides. While this sense of 'shared blame' may be true in some criminal cases, in many cases it is not. A victim in a rape or even a burglary does not want to be known as a 'disputant'. In fact, they may well be struggling to overcome a tendency to blame themselves. At any rate, to participate in most restorative justice encounters, a wrongdoer must admit to some level of responsibility for the offense, and an important component of such programs is to name and acknowledge the wrongdoing. The neutral language of mediation may be misleading and even offensive in such cases. Although the term 'mediation' was adopted early on in the field, for the above reasons it is increasingly being replaced by the terms such as 'conferencing' or 'dialogue'. 
do ponto de vista unicamente jurídico, uma vez que corresponde a um outro tipo de atitude e de posicionamento na administração e resolução dos conflitos, diferente daqueles mecanismos que tomam a lei como referência, consistindo, concretamente, na intervenção de um terceiro personagem imparcial - o mediador - distinto das partes, que atuará no sentido de favorecer o diálogo direto e pessoal entre elas. Observa-se, portanto, que se está diante de um modelo distinto do padrão conflitual de jurisdição, em que se lida com a oposição de interesses entre as partes, geralmente identificados como indivíduos isolados, convertidos, ao final, em um ganhador e um perdedor, e, desde o início, em um acusado e uma vítima.

Recorrer à mediação, portanto, implica em superar as funções operativas, míticas e políticas do sistema jurídico, isto é, em superar o imaginário normativista, para, em seu lugar, fazer surgir a possibilidade de uma resolução de conflitos que atenda à satisfação de todas as partes envolvidas, baseada em uma proposta autorregulada, com apoio de um mediador, que as auxilia no sentido de interpretar e transformar a situação problemática em que se encontram envolvidas. Nas palavras de Warat,

[...] na mediação nos encontramos com situações de reconstrução simbólica do conflito, realizada pelos diversos afetados, com a intervenção imparcial de um terceiro alheio ao conflito e sem poder de propor soluções, que têm que ser buscadas pelos próprios envolvidos na disputa. Mediação como modo de realizar um processo psíquico de reconstrução simbólica ${ }^{32}$.

O terceiro a que se refere Warat, diferencia-se do juiz e do árbitro, na medida em que esses se utilizam de sua posição de imparcialidade para decidir o conflito, conforme a lei, ao passo que o mediador, não podendo decidir pelas partes, apenas as ajuda naquela reconstrução simbólica do conflito. Ora, quando se decide o conflito - como o fazem o juiz e o árbitro, que ocupam um lugar de poder institucionalizado - seus efeitos são considerados normativamente, permanecendo latente na relação entre os envolvidos, podendo, no futuro, retornar de forma ainda mais agravada e violenta; no contexto da mediação, contudo, não se decide um conflito, mas se resolve, uma vez que as partes se veem diante da possibilidade de reconstruí-lo e, assim, transformá-lo, através de sua reinterpretação que ocorre, afinal, no processo mesmo de reconstrução. Caracteriza-se, portanto, a mediação, em termos de interpretação, pois, através da ajuda de um mediador, facilita-se

$\overline{32 \text { WARAT, op. cit., } 1998}$, p. 8. 
"a interpretação entre as partes, trabalhando os segredos do que foi enunciado como pretensão. Interpretando a história do conflito para transformá-lo, por seu reconhecimento, em uma inscrição simbólica"33.

Na verdade, o que se cogita, em se tratando de mediação, é o favorecimento da descoberta das intenções que se encontram por detrás das pretensões das partes em conflito. Não se trata, portanto, de oferecer às partes uma solução, mas, sim, oportunidades que estimulem a percepção e administração, com o outro, da diferença e da autonomia, e constituam instrumento que propicie a realização da autonomia, da democracia e da cidadania, "na medida em que educam, facilitam e ajudam a produzir diferenças e a realizar tomadas de decisões sem a intervenção de terceiros que decidem pelos afetados por um conflito", correspondendo, nesse sentido, a uma proposta ecológica de "transformação dos conflitos que apontam, mais que à decisão, a uma melhor qualidade de vida das partes envolvidas no conflito" ${ }^{\prime 4}$, sem necessariamente uma preocupação em ajustar o acordo daí resultante às disposições do direito positivo.

Como se vê, no sentido aqui exposto, o mediador tem, em muitos pontos, um papel similar ao do terapeuta - e, nesse sentido, distanciado da figura do conciliado, de atuação estreitamente limitada, no caso brasileiro, pela Lei no 9.099/1995 - uma vez que, no espaço da mediação, estabelecem-se

[...] vínculos transferenciais e contratransferenciais que exigem do mediador uma intervenção similar à do vínculo psicanalítico. Espera-se do mediador uma escuta similar à do psicanalista [...]. Uma intervenção sobre o discurso dos outros em conflito que respeite os tormentos de desejos que não são os do mediador. A escuta mediadora deve poder sentir o que se diz e o que não se diz quando

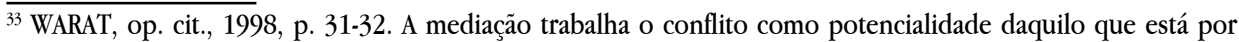
vir, do que de positivo pode ser construído sobre a matéria que constitui a disputa. No âmbito do sistema jurídico, particularmente do sistema jurídico-penal, dificilmente essa abordagem seria possível, uma vez que, nesse espaço, como já várias vezes referido, o conflito é congelado no tempo e demarcado em um plano de abstração jurídica que permita ao magistrado controlar as variáveis existentes, no sentido de organizar sua decisão. Desta forma, "os juízes terminam decidindo sobre diferentes posições teóricas do Direito, esquecidos dos conflitos reais que afetam a vida dos que foram decididos pelo Direito. São interpretações que legitimam decisões, roubando o tempo das partes: nos conflitos (transformados em litígios) submetidos à decisão dos tribunais de justiça, as partes perdem o direito de dispor do seu tempo. A variável temporal não influi na interpretação. $\mathrm{O}$ trabalho de interpretação fora da temporalidade não produz nenhuma formulação de sentido, unicamente produz uma fórmula. A interpretação judicial é um mecanismo de administração da polissemia, funciona como um aparato de controle, de burocratização dos sentidos. No poder judiciário se domesticam os sentidos, tentando, inutilmente, completar o que não se completa". WARAT, op. cit., 1998, p. 33.

${ }^{34}$ WARAT, op. cit., p. 6. Nessa medida, conforme entende WARAT, seriam mediáveis apenas conflitos de afetos, isto é, conflitos que incluem uma história, em que pelo menos uma das partes esteja implicada em uma relação de ódio, de amor ou de dor: "nos casos patrimoniais sem história, se decidem as diferenças, não existe conflito a resolver". WARAT, op. cit., p. 32.
} 
se diz algo, ou que outra coisa se está querendo dizer quando se diz algo. Também poder escutar, sem sua própria história de desejos reprimidos, o que se quer realmente quando se afirma querer algo. $\mathrm{O}$ mediador precisa saber escutar as outras coisas do querer (as coisas do querer de cada uma das partes) ${ }^{35}$.

Por essa abordagem se dar, na verdade, através da transformação do conflito, adequa-se àquilo que Morais e Silveira chamam de jurisconstrução. Isto é, em contraste com a ideia de jurisdição - caracterizada pela aplicação do direito como o exercício de um poder estatal - a mediação, nos termos acima tratados, incluiria um conceito de elaboração, concerto e construção da resposta ao conflito que reúne - e não opõe - as partes, restando ao Estado, desincumbido dos contenciosos de massa, a missão simbólica de referencial e a atividade concreta de instância de homologação e apelo ${ }^{36}$.

Raciocinando-se desta forma, seria possível abandonar a ideia de que um sistema de resolução de conflitos somente é eficaz se incluir a intervenção de instituições e procedimentos que abordem essas controvérsias a partir do ponto de vista controversial, em que a pretensa solução do problema é apresentada em termos de uma decisão ou de um acordo, em que, simplesmente, há a transferência de parcela do patrimônio, material ou simbólico, de uma parte - a perdedora para outra - a vitoriosa. Na verdade, como notam ainda Morais e Silveira, a via mais primitiva de resolução de disputas não se revestia de caráter judicial, sendo

\footnotetext{
${ }^{35}$ WARAT, op. cit., p. 38. Nada impede que o modelo psicanalítico venha a ser empregado nesse contexto de mediação de conflitos naturalmente reservados, no imaginário corrente, à abordagem judicial. Isto porque, se a psicanálise se destina a uma finalidade especial, que é a analítica, pode também ser aplicada em outros espaços, sem perder o seu rigor, desde que presente uma demanda concreta para sua utilização, sem a qual a interpretação, ainda que correta, pode ser experimentada como uma agressão. BRODSKY, Marcelo. Psicanálise e mediação. In: WARAT, Luiz Alberto (Org.). Em nome do acordo: a mediação no direito. Buenos Aires: ALMED, 1998, p. 60. Como afirma esse mesmo autor, a psicanálise, na realidade, nada mais é que uma mediação com um contrato diferente, de natureza analítica: "É com um enfoque analítico que um paciente vai à consulta em virtude de um sintoma que lhe é 'alheio' e também porque não compreende porque deve suportá-lo. A análise opera de forma a dissolver o sintoma pela descoberta de sua origem. Opera mediando no conflito que vive o sujeito, mediando entre o reprimido e a repressão e seus respectivos interesses. Do mesmo modo, o mediador, numa tentativa de resolução do conflito, se colocará em uma posição similar à do analista. Aos dois se supõe um saber que produzirá uma idealização por parte do paciente, no primeiro caso e, de pelo menos uma das partes na mediação. $\mathrm{O}$ trabalho do mediador consistirá em não ocupar esse lugar e delegar às partes, a responsabilidade do próprio desejo e, de guiar seus participantes a aceitar o outro como diferente, baseado nos interesses e posições conflitivas que se manifestem. Resumindo, a tarefa do mediador consiste em tentar que os sujeitos consigam verbalizar aquilo que está sob o manifestado e, que sem a consciência dos protagonistas, está produzindo o conflito. Melhor dizendo, o sintoma a resolver. Pode colocar em palavras o não-dito produz um alívio considerável permitindo que as partes exponham sobre o que realmente interessa: o conteúdo latente do conflito que os traz à mediação". BRODSKY, op. cit., p. 62.

${ }^{36}$ MORAIS, José Luís Bolzan de; SILVEIRA, Anarita Araújo da. Outras formas de dizer o direito. In: WARAT, Luiz Alberto (Org.). Em nome do acordo: a mediação no direito. Buenos Aires: ALMED, 1998, p. 88.
} 
que esse é que se tornou alternativo àqueles primeiros métodos ${ }^{37}$, o que reforça 0 reconhecimento do caráter subsidiário do direito, especialmente do direito penal, como instância de controle social.

Ao contrário da ideia de que um modelo de mediação como o aqui imaginado dificilmente poderia ser implementado, e de que se revestiria, por isso, de mero diletantismo acadêmico, pode-se lembrar das experiências bem-sucedidas de aplicação da chamada justiça restaurativa, sobretudo no âmbito do abuso de drogas e da juventude em conflito com a lei ${ }^{38}$.

Em todo caso, a perspectiva que se deve considerar para o futuro do espaço consensual inaugurado, no direito penal brasileiro, pela Lei no 9.099/1995, deve, mesmo que isso pareça contraditório, considerar sua localização exatamente fora do âmbito jurisdicional, ainda que sob controle desse, assegurando a observância das garantias constitucionais envolvidas. Isso porque, conforme analisa Warat, a deficiência do atual modelo, dentre outras razões, é representada pelo fato de sua implementação operacional ser atribuída à classe dos profissionais do direito, aqui representada pelo conciliador, pelo juiz e pelo promotor de justiça, referidos nos artigos 72 e seguintes da Lei ${ }^{0}$ 9.099/1995, "que não podem se desprender dos velhos vícios de seu ofício e práticas quando se colocam no papel de um mediador", contaminando "a mediação com um imaginário derivado do juridicismo improdutivo e inoperante, resultado do que eu chamo de o outro lado do ofício de mediador: o advogado que todo mediador é e não consegue reprimir"39. Seria, nesse contexto, portanto, a perspectiva a se considerar, a abordagem da resolução dos conflitos hoje tratados nos moldes do processo preliminar dos Juizados Especiais Criminais em

\footnotetext{
$\overline{{ }^{77} \text { Ibidem, 1998, p. } 70 .}$

${ }^{38}$ São frequentemente citados como exemplos, as experiências, nesse campo, no "Rio Grande de Sul (Justiça para o século XXI), São Paulo (nas escolas e na Justiça Infracional), no Distrito Federal (crimes de menor potencial ofensivo), Maranhão (na comunidade e na Justiça [em São José de Ribamar]), além do programa mineiro, no CIA-BH e no Juizado Especial Criminal-JECrim". LARA, Caio Augusto Souza. A justiça restaurativa como via de acesso à justiça. 2013. 101f. Dissertação (Mestrado em Direito) - Programa de Pós-Graduação em Direito, Universidade Federal de Minas Gerais, Belo Horizonte, p. 18. SANCHES, José Luiz. A transação penal no Juizado Especial Criminal como exercício de cidadania. 2006. 141f. Dissertação (Mestrado em Direito) Programa de Pós-Graduação em Direito, Universidade Presbiteriana Mackenzie, São Paulo, p. 134. Howard Zehr traz a informação de que "desde a década de 1970, uma variedade de programas e abordagens [restaurativos] têm surgido em milhares de comunidades e muitos países através do mundo. Frequentemente, tem-se a possibilidade de escolher entre esses e o sistema legal preexistente. Em 1989, entretanto, a Nova Zelândia fez da justiça restaurativa o centro de todo o seu sistema de justiça juvenil”. ZEHR, Howard; GOHAR, Ali, op. cit., p. 2 . No original: Since the 1970 s, a variety of programs and approaches have emerged in thousands of communities and many countries throughout the globe. Often these are offered as choices within or alongside the existing legal system. Starting in 1989, however, New Zealand has made restorative justice the hub of its entire juvenile justice system.

${ }^{39}$ WARAT, op. cit., 1998, p. 17.
} 
instância pré-judicial, ou seja, externa ao campo jurídico, capaz de promover "a reconstrução simbólica do conflito" ${ }^{\prime \prime}$, o que não poderia ser alcançado senão por profissionais das áreas da psicanálise, psicologia ou assistência social, por exemplo ${ }^{41}$.

Pode-se afirmar, contudo, que a composição dos danos civis e a transação penal, como mecanismos de despenalização e de alternativa à via jurisdicional strictu senso, conforme concebidas na Lei $\mathrm{n}^{\circ}$ 9.099/1995, constituem um importante esforço no sentido de oferecer efetivamente uma alternativa ao espaço da justiça punitiva, sendo a perspectiva que se vislumbra para o futuro, isto é, a instituição de mecanismos extrajudiciais de resolução do conflito, como fase preliminar de abordagem das situações criminalizáveis, particularmente adequada no caso de condutas que remetam a crimes contra a honra, crimes de ameaça e em casos de certos tipos de lesão corporal, em que há um envolvimento emocional mais intenso, assim como em casos de abuso de drogas e em certas situações de violência doméstica e familiar, podendo essas relações de afeto, como chamou Warat, ser objeto da reinterpretação construtiva que caracteriza sua concepção de mediação e que se encontraria, por definição, fora do âmbito do sistema de controle jurídicopenal, sendo, neste sentido, que se entende a devolução do conflito à comunidade - uma vez que deslegitimado o Estado como único ente capaz de oferecer a solução de controvérsias - e às partes envolvidas.

\section{CONSIDERAÇÕES FINAIS}

$\mathrm{O}$ presente artigo, nos limites a que se propôs, visou a oferecer uma visão crítica sobre os institutos trazidos ao ordenamento jurídico brasileiro pela Lei $\mathrm{n}^{0} 9.099$, de 26 de setembro de 1995 , no sentido da funcionalidade e eficácia, no âmbito dos Juizados Especiais Criminais, dos mecanismos de conciliação que inaugurou, seja no que se refere à composição dos danos civis, seja na composição da pena, essa através da transação penal, que implica certo grau de disponibilidade do exercício da ação penal por parte do representante do Ministério Público. Funcionalidade e eficácia essas no sentido da solução das situações problemáticas

\footnotetext{
${ }^{40}$ Idem.

${ }^{41}$ Segundo Zaffaroni, "a assistência social deve substituir a pena, com a advertência de que sempre deve ser levada a cabo com o mais absoluto respeito à dignidade da pessoa destinatária, porque não se trata de mudar o nome das coisas para que tudo permaneça como antes: deve-se cuidar para que a assistência social não se torne um meio tutelar tão repressor e estigmatizante como a pena" (ZAFFARONI, Eugenio Raúl. Política criminal latinoamericana: perspectivas, disyuntivas. Buenos Aires: Hammurabi, 1982, p. 92).
} 
que são apresentadas a essa instância de controle jurídico-penal, concluindo-se que, potencialmente, nos moldes em que hoje se apresentam aqueles mecanismos, tenderiam eles mais propriamente para a obtenção do "fim do processo" do que para o alcance do "fim do conflito".

Para além dessa crítica, procurou-se vislumbrar a possibilidade de avanços no sentido da adoção de práticas restaurativas ou de jurisconstrução, naquilo que se tem chamado de "quarto movimento" do acesso à justiça, isto é, da busca da pacificação dos conflitos abordados pelo direito penal fora dos limites do aparelho judiciário do Estado.

A perspectiva descrita foi analisada a partir da ideia de mediação desenvolvida pelo Professor Doutor Luis Alberto Warat - a quem, aqui, procurou-se fazer uma homenagem - para quem a pacificação dos conflitos interpessoais somente seria possível ou, antes, seria mais bem favorecida, através de uma abordagem que desse conta da identificação do conflito subjacente àquele que é anunciado pelos envolvidos e apresentado para apreciação do Estado, em algo que em muito se aproxima da concepção psicanalítica.

Em 20 anos da vigência da Lei $n^{0}$ 9.099/1995, muito se avançou na compreensão da necessidade de se buscarem soluções consensuais ou mesmo extrapenais ou extrajudiciais para os conflitos até então tratados exclusivamente pelo viés punitivo, que constitui a mais violenta e, não raro, desproporcional resposta do Estado. Nos anos vindouros, muito ainda se há de compreender, nesse sentido, com a perspectiva de um avanço em direção a um modelo, que, de fato, ofereça a possibilidade de restauração dos laços intersubjetivos ou comunitários rompidos ou enfraquecidos pela erupção de situações problemáticas.

\section{REFERÊNCIAS}

ANDRADE, Manuel da Costa. A vítima e o problema criminal. Coimbra: Coimbra, 1980.

ANDRADE, Vera Regina Pereira de. A ilusão da segurança jurídica: do controle da violácea à violência do controle penal. Porto Alegre: Livraria do Advogado, 1997.

BECKER, Howard. Outsiders: studies in the sociology of deviance. New York: The Free Press, 1973. 
BARTHES, Roland. Théorie du texte. Atelier des Sciences du Langage de l'Université Paul-Valéry - Montpellier 3. Eléments de linguistique et de communication. Disponível em: <http://asl.univ-montp3.fr/e41slym/Barthes_THEORIE_DU_TEXTE.pdf > . Acesso em: 03 maio 2015

BRODSKY, Marcelo. Psicanálise e mediação. In: WARAT, Luiz Alberto (Org.). "Em nome do acordo: a mediação no direito". Buenos Aires: ALMED, 1998.

CAPPELLETTI, Mauro.; GARTH, Bryant. Acesso à Justiça. Tradução Ellen Gracie Northfleet. Porto Alegre: Fabris, 1988.

CARNEIRO, J. G. P. A justiça do pobre. Revista da Amagis, Belo Horizonte, v. 1, n. 1, p. 146-151, 1983.

CONSULTOR Jurídico. Morre professor argentino Luis Alberto Warat. Disponível em: $\quad<$ http://www.conjur.com.br/2010-dez-17/morre-teorico-professor-argentinoluis-alberto-warat $>$. Acesso em: 03 maio 2015.

DIAS, Figueiredo; ANDRADE, Manuel da Costa. Criminologia: o homem delinquente e a sociedade criminógena. Coimbra: Coimbra, 1992.

FERRAZ JÚNIOR, Tércio Sampaio. A ciência do direito. 2. ed. São Paulo: Atlas, 1980.

GOFFMAN, Erving. Estigma: notas sobre a manipulação da identidade deteriorada. 4. ed. Rio de Janeiro: Guanabara, 1988.

GRINOVER, Ada Pellegrini; GOMES FILHO, Antônio Magalhães; FERNANDES, Antônio Scarance; GOMES, Luiz Flávio. Juizados especiais criminais. 2. ed. São Paulo: RT, 1997.

LARA, Caio Augusto Souza. A justiça restaurativa como via de acesso à justiça. 2013. 101f. Dissertação (Mestrado em Direito) - Universidade Federal de Minas Gerais, Belo Horizonte, 2013.

LAVORENTI, Wilson; SILVA, José Geraldo da. Crime organizado na atualidade. Campinas: Bookseller, 2000.

KARAN, Maria Lúcia. Juizados especiais criminais: a concretização antecipada do poder de punir. São Paulo: RT, 2004.

KYLE, Linda Dee. Transação penal: revisão crítica à luz do acesso à justiça. Curitiba: Juruá, 2011. 
MENDES, Gilmar Ferreira. Apresentação. In: HASSEMER, Winfried. Direito penal libertário. Belo Horizonte: Del Rey, 2007.

MERTON, Robert K. Social theory and social structure. Enl. ed. New York: The Free Press, 1968.

MORAIS, José Luís Bolzan de; SILVEIRA, Anarita Araújo da. Outras formas de dizer o direito. In: WARAT, Luiz Alberto (Org.). "Em nome do acordo: a mediação no direito". Buenos Aires: ALMED, 1998, p. 68-98.

PEREIRA, Júlia Lafayette. Implicações do discurso eficientista neoliberal no movimento de ampliação do acesso à justiça: a experiência dos juizados especiais federais. 2013. 171f. Dissertação (Mestrado em Direito) - Universidade do Vale dos Sinos, São Leopoldo, 2013.

SANCHES, José Luiz. A transação penal no juizado especial criminal como exercício de cidadania. 2006. 141f. Dissertação (Mestrado em Direito) - Universidade Presbiteriana Mackenzie, São Paulo, 2006.

SANTOS, Boaventura de Sousa. Para uma revolução democrática da justiça. 3. ed. São Paulo: Cortez, 2011.

VIANA, Fábia de Kássia Mendes. Os juizados especiais como mecanismo de acesso à justiça. Via Jus. Disponível em: <http://www.viajus.com.br/viajus. php? pagina $=$ artigos\&id $=553 \&$ idAreaSel $=16 \&$ seeArt $=$ yes $>$. Acesso em: 03 maio 2015.

VIANNA, Luiz Werneck; MELO, Manuel Palacios Cunha; CARVALHO, Maria Alice Rezende de. A judicialização da política e das relações sociais no Brasil. Rio de Janeiro: Revan, 1999.

WARAT, Luiz Alberto. Ecologia, psicanálise e mediação. In: WARAT, Luiz Alberto (Org.). "Em nome do acordo: a mediação no direito". Buenos Aires: ALMED, 1998.

WARAT, Luiz Alberto. Introdução geral do direito I: interpretação da lei: temas para uma reformulação. Porto Alegre: Fabris, 1994. v. 1. 
ZAFFARONI, Eugenio Raúl. Política criminal latinoamericana: perspectivas, disyuntivas. Buenos Aires: Hammurabi, 1982.

ZANATTA, Rafael. Luis Alberto Warat: contra o senso comum teórico dos juristas. E-MANCIPAÇÃO, 16 de dezembro de 2010. Disponível em: < http://rafazanatta. blogspot.com.br/2010/12/luis-alberto-warat-contra-o-senso-comum.html >. Acesso em: 03 maio 2015.

ZANATTA, Rafael. O que é o movimento waratiano? E-MANCIPAÇÃO, 5 de setembro de 2012. Disponível em: < http://rafazanatta.blogspot.com.br/2012/09/o-que-e-omovimento-waratiano.html> . Acesso em: 3 maio 2015.

Recebido em: 31 de agosto de 2015 Aceito em: 22 de dezembro de 2015 